\title{
ERGONOMIA PARA IDOSOS EM AMBIENTES RELIGIOSOS: CONSIDERAÇÕES PARA O ESTUDO DE CASO DE UMA IGREJA CATÓLICA
}

\author{
ERGONOMICS FOR ELDERLY PEOPLE IN RELIGIOUS \\ ENVIRONMENTS: CONSIDERATIONS FOR THE CASE STUDY OF A \\ CATHOLIC CHURCH
}

Wynne Souza de Melo ${ }^{1}$, Bel.

Bruno Xavier da Silva Barros², MSc.

José Adilson da Silva Júnior ${ }^{3}$, Esp.

(1) Universidade Federal de Pernambuco (UFPE-CAA).

e-mail: wynne melo@hotmail.com

(2 Universidade Federal de Pernambuco (UFPE-CAA).

e-mail: barrosbruno@hotmail.com

(3) Universidade Federal de Pernambuco (UFPE).

e-mail: silvajunior.adilson@hotmail.com

Palavras-chave: Idosos, igreja católica, ergonomia do ambiente construído.

As igrejas são comumente frequentadas por pessoas idosas, para tanto, deve proporcionar um ambiente confortável e acolhedor. Este artigo aborda questões relacionadas à maneira como o envelhecimento humano compromete a autonomia dos idosos, bem como a forma pela qual o Design e a Ergonomia do Ambiente Construído podem contribuir para uma adequação do ambiente interno de uma igreja, de modo que as dificuldades encontradas por esses indivíduos sejam solucionadas ou minimizadas. A partir da Metodologia para Projetos de Construção Centrados no Usuário, proposta por Attaianese e Duca (2012); pesquisa bibliográfica; entrevistas e observações, munidas de ferramentas de registro e de medição, em uma igreja católica localizada em uma cidade do interior de Pernambuco, foi possível estabelecer propostas de recomendações que norteiam o processo adaptativo de igrejas, focado no conforto e bem-estar dos idosos.

Key-words: Elderly, catholic church, ergonomics of the built environment.

The churches are commonly frequented by elderly people, for that, it should provide a comfortable and warm environment. This article addresses issues related to how human aging compromises the autonomy of the elderly, as well as the way in which the Design and Ergonomics of the Built Environment can contribute to an adequacy of the internal environment of a church, so that the difficulties encountered by these individuals are solved or minimized. from the Methodology for Human-centred Building Design by Attaianese and Duca (2012); bibliographic research; interviews and observations, equipped with registration and measurement tools, in a catholic church located in a city in the interior of Pernambuco, it is possible to arrive at proposals for recommendations that guide the adaptive process of churches, focused on the comfort and well-being of elderly. 
$16^{\circ}$ Ergodesign - Congresso Internacional de Ergonomia e Usabilidade de Interfaces Humano Tecnológica: Produto, Informações Ambientes Construídos e Transporte

$16^{\circ}$ USIHC - Congresso Internacional de Ergonomia e Usabilidade de Interfaces Humano Computador

CINAHPA | 2017 - Congresso Internacional de Ambientes Hipermídia para Aprendizagem.

\section{Introdução}

Com o crescente envelhecimento da população mundial e suas consequentes demandas, as pesquisas em ergonomia voltadas para o público idoso tornam-se uma ferramenta importante na busca pela melhoria da qualidade de vida.

De acordo com Iida (2005), a Ergonomia baseia-se no entendimento do ser humano para projetar de maneira adequada às suas capacidades e restrições, tornando os postos de trabalho, produtos, e sistemas, compatíveis com suas necessidades. Entre os diversos campos onde a Ergonomia pode atuar, está o design de interiores.

O design de interiores é uma área do estudo que tem o objetivo de arranjar os ambientes de acordo com as necessidades do usuário, levando em consideração o conforto, a funcionalidade e a estética, atentando para o projeto e distribuição dos móveis, objetos, cores, materiais, acabamentos. $\mathrm{O}$ ambiente acaba por se tornar uma extensão do ser humano na sua forma de viver, como habitante, trabalhador, no seu convívio social, e, por este motivo, pessoas e ambientes não podem ser pensados separadamente. Os projetos precisam, portanto, levar o ser humano em consideração, propondo ambientes funcionais e confortáveis para todos os tipos de usuário. Logo, este pensamento se aplica também a ambientes públicos, templos e monumentos de adoração e profissão da fé, como a igreja católica.

O ambiente da igreja, que historicamente faz parte da cultura da sociedade, é um local comumente frequentado por vários tipos de usuário, sendo os idosos um dos públicos mais assíduos. A igreja católica, que possui inúmeras construções antigas, muitas das quais já tombadas como patrimônio histórico e cultural, geralmente apresenta em seu interior alguns aspectos limitantes relacionados à utilização do ambiente, o que faz com que os idosos sofram com algumas dificuldades decorrentes do envelhecimento.

O processo natural de envelhecimento impõe gradativamente sintomas limítrofes, como a rigidez articular e diminuição da amplitude de movimento, redução do tônus muscular, onde o sentar-se, o ajoelhar-se, e o levantar-se, que antes eram ações simples e desempenhadas sem grandes esforços, passa a figurar um problema motor. Partindo desse pressuposto, podemos observar que o ambiente interno das igrejas não considera as necessidades específicas e limitações físicas desses usuários, e essa ausência de adaptações pode causar desconfortos e lesões.

Dentro deste contexto, a corrente pesquisa repousou o olhar sobre a necessidade de análise do ambiente religioso de uma igreja católica para, a partir de então, prover recomendações para o norteamento adaptativo do ambiente interno de igrejas católicas, com foco na utilização por parte do idoso. Para tanto, fez-se necessário identificar as limitações físicas decorrentes do processo natural de envelhecimento; e identificar os prejuízos ergonômicos decorrentes da utilização do ambiente interno da igreja por parte de indivíduos idosos.

A significância da presente pesquisa reside no fato de fornecer para o design, parâmetros e recomendações ergonômicas que devem ser levadas em consideração para o projeto de igrejas, focado no conforto e no bem-estar de um dos seus usuários mais frequentes, os idosos.

Tendo em vista que, devido ao processo natural de envelhecimento, os idosos sofrem uma grande perda da independência e de capacidades motoras, este estudo espera contribuir para uma melhoria na qualidade de vida, propondo formas de correção e prevenção de dificuldades encontradas por esses indivíduos no ambiente da igreja, proporcionando conforto e segurança.

A partir do estudo de caso do ambiente interno de uma igreja católica de uma cidade do interior de Pernambuco, foi possível identificar quais, e de que forma, os fatores observados agem como aspectos limitantes para os idosos. Para tanto, lançamos mão da Metodologia para Projetos de Construção Centrados no Usuário, proposta por Attaianese e Duca (2012). 
$16^{\circ}$ USIHC - Congresso Internacional de Ergonomia e Usabilidade de Interfaces Humano Computador

CINAHPA | 2017 - Congresso Internacional de Ambientes Hipermídia para Aprendizagem.

\section{Fundamentação teórica}

\subsection{Idosos e processo de envelhecimento}

Envelhecer é um processo que faz parte do ciclo natural da vida, e traz consigo algumas mudanças, por vezes, muito complexas. A OMS (2015) aponta que biologicamente o envelhecimento se relaciona ao acúmulo de uma ampla variedade de prejuízos moleculares e celulares que, ao longo dos anos, induz a uma perda gradativa das reservas

fisiológicas e o indivíduo torna-se mais propenso a adquirir inúmeras doenças, havendo também uma decadência na capacidade intrínseca do indivíduo.

De acordo com lida (2005), o processo de envelhecimento gera uma deterioração crescente da função cardiovascular, potência muscular, flexibilidade articular, órgãos dos sentidos e da função cerebral. Ainda segundo o autor, o processo se inicia em torno dos 30 a 40 anos, e a partir dos 50 anos tende a se acelerar. Essas degradações progressivas geram a incapacidade funcional que, conforme Bonardi et al. (2007), é o processo dinâmico e progressivo, decorrente das doenças crônico degenerativas e de alterações fisiológicas agregadas ao envelhecimento, podendo acontecer de maneira aguda, como, por exemplo, no acidente vascular cerebral e na fratura femoral, que ocasionam limitações funcionais, estas, por sua vez, ainda segundo os autores, restringem a prática de ações físicas e processos mentais essenciais para a vida diária, comparando-se aos indivíduos de mesmo gênero e idade.

Para Iida (2005), o envelhecimento pode afetar as funções fisiológicas, sendo elas: antropometria, força muscular, processos cognitivos, visão e audição. No nível antropométrico, a estatura das pessoas passa a sofrer uma diminuição gradativa após os 50 anos; já na antropometria dinâmica, os alcances e flexibilidade sofrem uma redução, principalmente nos membros superiores (IIDA, 2005).

A força muscular começa a enfraquecer e, segundo Polato (2010), isso se relaciona diretamente com a diminuição da massa muscular que acontece com a idade. Este fato está explicitamente ligado ao tônus muscular que, segundo o autor, compreende muitos atributos distintos, como elasticidade, viscosidade e contração, tendo grande relevância nas funções ligadas ao controle motor e estabilidade articular. Ou seja, a perda de tônus muscular compromete a execução de atividades que demandam força.

Em relação aos processos cognitivos, estes são afetados principalmente no que se refere ao processamento de estímulos e tempo de reação. De acordo com Iida (2005), esse declínio associa-se à dificuldade de manter novas informações na memória de curta duração. $O$ autor também afirma que a diminuição na capacidade desta memória é pouca, porém as informações são mantidas por menos tempo, o que é armazenado temporariamente pode ser perturbado facilmente, e isto costuma se agravar em pessoas muito velhas, que estão suscetíveis a esquecer o objetivo da ação, na fase de execução do ato.

A visão, como afirma Esquenazi et al. (2013), é um sistema bastante complexo que envolve a integração entre as estruturas do olho e os controles neural e motor. Este sentido tem como função obter informações acerca do ambiente, as quais servirão de guia para a movimentação do corpo. Na visão, o envelhecimento age como um redutor da transparência do cristalino, diminuindo sua elasticidade e afetando os músculos que o controlam, comprometendo assim a acomodação dos olhos, responsável pela focalização de objetos próximos. Há também perda de acuidade, habilidade de perceber detalhes, onde o cristalino e o humor vítreo perdem transparência, fazendo com que os idosos precisem de luzes mais intensas (IIDA, 2005).

Tratando da audição, segundo Baraldi et al. (2007), os danos aditivos relacionados ao envelhecimento referem-se à um conjunto de perdas auditivas resultantes de muitos tipos de deteriorações fisiológicas, inclusive os prejuízos decorrentes de agentes ototóxicos, tratamentos médicos e exposição a ruídos. As autoras ainda afirmam que as alterações decorrentes do avançar da idade no sistema auditivo periférico, inter-relacionam-se
Realização:

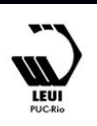




\section{$16^{\circ}$ \\ ERGODESIGN USIHC CINAHPA}

$16^{\circ}$ Ergodesign - Congresso Internacional de Ergonomia e Usabilidade de Interfaces Humano Tecnológica: Produto, Informações Ambientes Construídos e Transporte

$16^{\circ}$ USIHC - Congresso Internacional de Ergonomia e Usabilidade de Interfaces Humano Computador

CINAHPA | 2017 - Congresso Internacional de Ambientes Hipermídia para Aprendizagem. com mudanças na redução do suporte cognitivo, da compreensão e elevação de limiares, e da assimilação de fala no ruído, afetando na localização do som e na percepção de mudanças rápidas na fala.

Ocorrem também alterações musculoesqueléticas e ósseas, segundo Esquenazi et al. (2013), depois dos 35 anos, mudanças na cartilagem articular, as quais provocam, junto com alterações

biomecânicas possivelmente adquiridas, diversas degenerações que podem acarretar num declínio na capacidade de locomoção e flexibilidade, aumentando assim o risco de lesões. Fatores como obesidade e hereditariedade também podem contribuir com o aparecimento de problemas ligados a essas alterações.

Podemos observar que o envelhecimento do organismo humano é crescente e progride irreversivelmente, tornando o indivíduo mais vulnerável aos acometimentos dos meios interno e externo. No entanto, não significa dizer que este processo é o único fator que acarreta limitações e perda de independência, pois isso dependerá de questões intrínsecas e vai variar de idoso para idoso (MORAES, 2008).

Um ponto que dificulta o entendimento sobre as necessidades dos idosos, podendo interferir na criação de políticas públicas eficazes direcionadas aos indivíduos senis, é o conceito de velhice existente no imaginário social que, na maioria dos casos faz uma associação muito negativa em relação ao envelhecimento. Como relata Veras (2009), a precariedade de investimentos públicos para dar suporte às necessidades específicas das pessoas idosas, soma-se à desinformação, ao preconceito e ao desrespeito para com os cidadãos da terceira idade. Isto pode ser chamado de discriminação etária e está relacionada aos estereótipos comumente atribuídos, refletindo em ideias distorcidas sobre a velhice. Cria-se um estigma em torno da velhice, assimilando-a às transformações que o corpo tende a sofrer com o passar dos anos, modificando a aparência física, percebida de imediato pela sociedade, mesmo que não haja contato direto, e isto acaba por contribuir com a rejeição que se tem pelo envelhecimento (MORAES, 2007).

\subsection{O ser humano no ambiente construído}

Tendo em vista que os fatores ambientais influenciam diretamente no comportamento humano, e repercutem no seu bem-estar, é importante que se compreenda se os ambientes concebidos pelo homem estão de acordo com as necessidades dos seus usuários. Neste sentido, a Ergonomia do Ambiente Construído torna-se essencial, por ultrapassar questões fundamentalmente arquitetônicas e se focar nos fatores adaptativos e de compatibilidade que os ambientes apresentam em relação às atividades que nele vão ser desenvolvidas, por intermédio da visão dos usuários (VILLAROUCO, 2007).

Segundo Paiva e Villarouco (2012), os seres humanos tendem a reagir de maneira distinta aos estímulos físicos de cada ambiente, por possuírem um sistema passivo. Neste sentido, os ambientes podem acabar gerando desconfortos ou doenças ocupacionais, influenciando na segurança e qualidade de vida dos usuários.

Trazendo o foco para esta pesquisa, entende-se que é fundamental que esses fatores sejam considerados nos projetos de adequação do ambiente construído, pois isto pode facilitar a utilização de ambientes pelos usuários idosos, podendo interferir positivamente na qualidade de vida. Portanto, como afirma Sobral et al. (2015), a concepção de ambientes que favoreçam o desempenho de atividades desta camada da população, os possibilita condições mais saudáveis e produtivas de se viver, não deixando de favorecer, também, os demais indivíduos da sociedade.

Para um projeto centrado no ser humano, é fundamental que se conheça detalhadamente as tarefas passíveis de realização em cada ambiente, e as características e instrumentos necessários à sua realização. Neste sentido, os indivíduos a quem se destina o ambiente devem participar das etapas de projeto, fornecendo informações sobre questões
Realização:

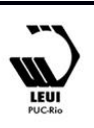




\section{$16^{\circ}$ \\ ERGODESIGN USIHC CINAHPA}

$16^{\circ}$ Ergodesign - Congresso Internacional de Ergonomia e Usabilidade de Interfaces Humano Tecnológica: Produto, Informações Ambientes Construídos e Transporte

$16^{\circ}$ USIHC - Congresso Internacional de Ergonomia e Usabilidade de Interfaces Humano Computador

CINAHPA | 2017 - Congresso Internacional de Ambientes Hipermídia para Aprendizagem. operacionais, organizacionais e cognitivas, o que pode ser feito através de mapas mentais, que é a representação gráfica do que o usuário espera de um ambiente adaptado às suas necessidades, seguido de mapas cognitivos, que permitem a construção de uma rede de informações direcionadas a um fỉm, e possibilitam a concepção de um check list, partindo da representação mental que o usuário tem em relação ao tipo de espaço que está sendo abordado (VILLAROUCO, 2004).

\subsection{Ambiente interno das igrejas}

Profundamente enraizada na história e na cultura de muitas sociedades, a igreja católica foi implantada no Brasil pelos missionários que acompanharam os colonizadores portugueses em 1500 , com o intuito de expandir o catolicismo através da evangelização (COUTO, 2012).

Com características únicas e peculiares, o ambiente interno das igrejas apresenta diversos aspectos a serem explorados. Após a renovação da liturgia pelo Concílio Vaticano em 1963, ocorreram mudanças na organização do ambiente da igreja, havendo uma retomada à simplicidade e a funcionalidade, ficando estabelecido que as novas igrejas atendessem à liturgia renovada, e as antigas igrejas fossem conservadas e adaptadas (MILANI, 2006).

No edifício da igreja católica, existem alguns espaços característicos e essenciais da arquitetura, dentre os quais, podemos apontar: Átrio, Nave, Presbitério, Capela do Santíssimo, Batistério e Sacristia.

De acordo com Milani (2006), o Átrio é o hall de entrada, que na arquitetura cristã possui grande importância, pois simboliza um lugar de transição e separação entre o mundo profano (exterior) e sagrado (interior). A Nave, como cita a autora, é o lugar onde a assembleia se reúne e fica disposta durante a celebração e executa os ritos de sentar-se, ficar de pé, ajoelhar-se, transitar pela igreja e aproximar-se do altar, de acordo com o momento da celebração. O Presbitério é o lugar onde o celebrante preside as cerimônias acompanhado pelos ministros eucarísticos, e possui três peças essenciais: o Altar (a peça mais importante da igreja, corresponde a mesa da Eucaristia), o Ambão (onde as leituras bíblicas são realizadas) e a Cadeira da Presidência. A capela do Santíssimo é o lugar onde está localizado o Sacrário, que funciona como cofre para resguardar as hóstias eucarísticas. Por fim, o Batistério, lugar onde está localizada a fonte batismal na qual se realizam os batismos (MILANI, 2006). Além destes espaços, outros elementos importantes na arquitetura católica, segundo Lima (2010), são o piso, o teto, as paredes e os vitrais.

\section{Procedimentos Metodológicos Adotados}

O referente estudo caracteriza-se como indutivo, cuja característica principal reside na possibilidade de generalização dos resultados de um estudo de caso. Como procedimento, lançamos mão da Metodologia para Projetos de Construção Centrados no Usuário, proposta por Attaianese e Duca (2012).

A metodologia concebida por Attaianese e Duca (2012), divide-se em sete etapas, a saber: 1| Briefing de Design; 2| Perfis de Usuários e Grupos de Ajuste; 3| Análise da Tarefa; 4| Adaptação às Necessidades dos Usuários; 5| Primeiros Detalhes Arquitetônicos; 6| Validação das Soluções de Design; 7| Avaliação da Edificação em Uso. Entretanto, as etapas 5, 6 e 7 não foram adotadas na referente pesquisa, uma vez que os objetivos deste trabalho se baseiam apenas na proposição de recomendações generalizadas para ambientes similares e também por não se tratar de um estudo projetual.

Dentre as etapas contempladas neste estudo, a etapa de Briefing de Design busca reunir informações sobre os requisitos necessários ao ambiente para satisfazer as demandas dos usuários e, para isso, pode se utilizar de algumas ferramentas de coleta de dados como entrevistas e questionários.

Na segunda etapa, Perfis de Usuários e Grupos de Ajuste, é feita a descrição dos indivíduos e são
Realização:

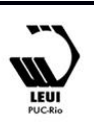




\section{$16^{\circ}$ \\ ERGODESIGN USIHC CINAHPA}

$16^{\circ}$ Ergodesign - Congresso Internacional de Ergonomia e Usabilidade de Interfaces Humano Tecnológica: Produto, Informações Ambientes Construídos e Transporte

$16^{\circ}$ USIHC - Congresso Internacional de Ergonomia e Usabilidade de Interfaces Humano Computador

CINAHPA | 2017 - Congresso Internacional de Ambientes Hipermídia para Aprendizagem. reconhecidos os grupos de usuários (diretos e indiretos), suas características pessoais e estado de uso do ambiente. As capacidades físicas, cognitivas e socioculturais identificadas dos usuários em questão, devem ser especificadas a fundo, para que as características técnicas do projeto se adaptem ao público-alvo da melhor maneira possível.

A Análise da Tarefa, terceira etapa metodológica, destina-se a descrever as observações sistemáticas e assistemáticas, e identificar as atividades realizadas no ambiente pelo usuário em foco, sendo verificados os objetivos que se pretende atingir, quais os requisitos necessários, de que meios o usuário se utiliza, posturas assumidas na realização das tarefas, condições e constrangimentos do ambiente.

A quarta etapa, Adaptação às Necessidades dos Usuários, consiste na compilação de todos os dados obtidos nas etapas anteriores, que indicarão as características necessárias para satisfazer as demandas e expectativas dos usuários acerca do ambiente construído. Gerando, ao final, a lista de recomendações ergonômicas.

\subsection{Apresentação do local do Estudo de Caso}

A igreja selecionada para o estudo de caso (Figura 1), está localizada em uma cidade do Agreste Meridional do estado de Pernambuco, distante 206 km da capital Recife e com pouco mais de 57 mil habitantes.

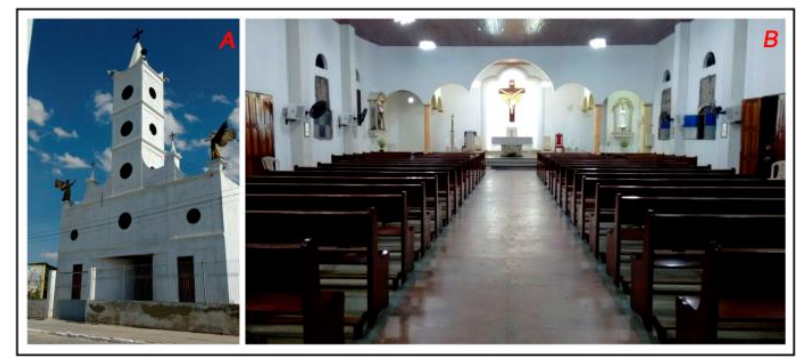

Figura 1: A) fachada da igreja selecionada para o estudo de caso. B) interior da igreja. Fonte: Capturado pelos autores para a pesquisa.

Fundada em 1981, a igreja atende, desde então, um público diversificado variando entre idosos, adultos, jovens e crianças. Encontra-se aberta para missas aos domingos ( $8 \mathrm{~h}$ e $17 \mathrm{~h}$ ) e quartas-feiras (19h30min). Além disso, a igreja também abre toda primeira sexta-feira de cada mês, às $15 \mathrm{~h}$, e todo dia 18, às 19h30min para missas especiais. Aos sábados à noite são realizados casamentos em horários variados, e, no segundo domingo de cada mês, após a missa da manhã, acontecem os batizados.

\section{Resultados obtidos}

\subsection{Briefing de Design}

O ambiente interno da igreja necessitava de algumas condições específicas. Deve-se pensar no piso para evitar quedas, e confusão visual, para oferecer segurança na circulação. Faz-se necessário estudar a iluminação, de modo que se evite a geração de sombras que possam ocasionar quedas. Deve-se pensar ainda na temperatura, de modo que o ambiente ofereça um equilíbrio térmico, e os níveis de ruído devem ser observados e controlados para não ultrapassar os limites de tolerância. Também deve ser analisada a aeração no local, para que a velocidade do vento seja controlada, caso esteja além do permitido.

O mobiliário, neste caso os bancos, precisam ser confortáveis, acolchoados e com dimensões adequadas. O genuflexório (pequeno móvel de madeira, fixo ou móvel, onde os fiéis se ajoelham para rezar), que neste caso é agregado a parte de trás dos bancos, devem também oferecer o máximo de conforto possível, já que se ajoelhar já é por si uma atividade desconfortável. As cores e contrastes precisam estar em equilíbrio, de modo que torne $\mathrm{o}$ ambiente estimulante e acolhedor.

O ambiente deve oferecer um layout que facilite a visualização do altar, e ofereça também espaços de circulação amplos e sem barreiras físicas. Através desta etapa ficam então identificadas algumas condições necessárias, sugeridas pelos usuários, para uma utilização plena, segura e satisfatória do ambiente. 


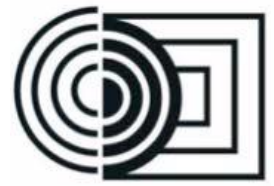
CINAHPA

\subsection{Perfis de Usuário e Grupos de Ajuste}

Os usuários diretos do ambiente aqui estudado abrangem um público diversificado que varia entre idosos, adultos, jovens e crianças. No entanto, nos detivemos nos idosos, foco desta pesquisa. Podendo ter algumas de suas capacidades fisiológicas afetadas pelo processo natural de envelhecimento, os idosos usuários diretos neste estudo, apresentam, não obrigatoriamente todos, uma diminuição da força muscular, diminuição da estatura, redução dos alcances e flexibilidade (principalmente dos membros superiores), problemas na visão, perdas auditivas, diminuição das capacidades cognitivas de processamento de estímulos e tempo de reação, além de uma degeneração musculoesquelética, ou problemas de obesidade e/ou hereditariedade, que podem acarretar no declínio da flexibilidade e capacidade de locomoção tornando o idoso mais suscetível a lesões.

Os usuários indiretos são os católicos não praticantes, que frequentam a igreja eventualmente, ou visitantes, que também podem ser idosos, adultos, jovens e crianças, possuindo níveis distintos de capacidade e autonomia física.

\subsection{Análise da Tarefa}

A fase de Análise da Tarefa teve sua aplicação justificada pela necessidade de se observar as tarefas realizadas no ambiente da igreja pelos usuários analisados, bem como a forma como eles as realizam, atentando para possíveis posturas nocivas assumidas na execução das tarefas, e as potenciais lesões ou acidentes que podem acarretar. Inserimos nesta fase uma verificação dos índices de iluminação, ruído e temperatura aferidos no local do estudo de caso, comparando-os com as taxas recomendadas pela legislação. Finalizando a etapa de Análise da Tarefa, agregamos uma análise antropométrica dos artefatos e da circulação do ambiente.

\subsubsection{Ajoelhar-se}

Além de já ser uma tarefa complexa devido à $16^{\circ}$ Ergodesign - Congresso Internacional de Ergonomia e Usabilidade de Interfaces Humano Tecnológica: Produto, Informações Ambientes Construídos e Transporte

$16^{\circ}$ USIHC - Congresso Internacional de Ergonomia e Usabilidade de Interfaces Humano Computador

CINAHPA | 2017 - Congresso Internacional de Ambientes Hipermídia para Aprendizagem.

pouca força física e aos problemas articulares e dificuldade de mobilidade (comum nos idosos), o ato de se ajoelhar mostrou-se incômodo pela ausência de genuflexório (não disponível para quem senta nos bancos da frente) fazendo com que o idoso se ajoelhe no chão (Figura 07: A e B), podendo causar ferimentos nos joelhos e dores nas articulações dos membros inferiores.

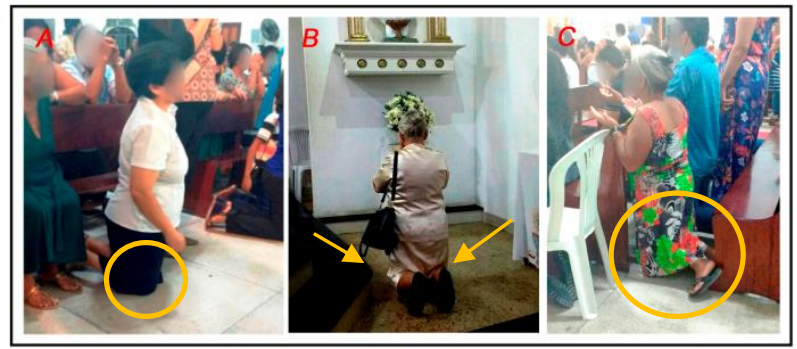

Figura 2: tarefa de ajoelhar-se. Fonte: elaborado pelos autores para a pesquisa (2016).

O genuflexório disponível nos demais bancos da assembleia é feito do mesmo material rígido do banco, mostrando-se muito desconfortável, além de diminuir o espaço (já reduzido) entre um banco e outro, podendo causar contusões ou até mesmo quedas.

\subsubsection{Levantar-se}

Também com um nível de dificuldade elevado, esta tarefa, mostrou-se incômoda pelo fato do idoso não contar com algum tipo de apoio para o auxiliar, tendo que fazer bastante esforço físico, com os membros inferiores (principalmente), muitas vezes se apoiando em superfícies inadequadas, que podem levá-lo a uma queda ou lesão na coluna vertebral gerada por apoio assimétrico.

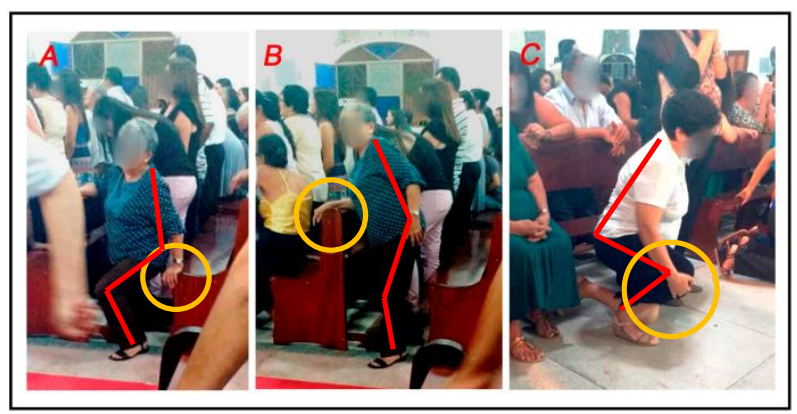

Figura 3: tarefa de levantar-se. Fonte: elaborado pelos autores para a pesquisa (2016).
Realização:

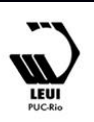




\section{$16^{\circ}$ \\ ERGODESIGN USIHC CINAHPA}

Também é possível observar na figura 08 que, durante este processo de se erguer, o idoso acaba assumindo posturas inadequadas, podendo causar riscos de danos musculoesqueléticos. Além disso, a tarefa pode gerar para o idoso o constrangimento de ter que pedir ajuda para levantar.

\subsubsection{Ficar de pé}

A tarefa de permanecer de pé em variados momentos das celebrações na igreja, pode tornar-se cansativa, se for realizada durante longos períodos de tempo. Como visto na figura 09 (B) e (C), ao permanecer muito tempo de pé, os idosos tendem a buscar apoio em objetos próximos, o que não é o mais adequado, pois isso pode fazer com que assumam posturas nocivas à saúde com possíveis danos à coluna vertebral.

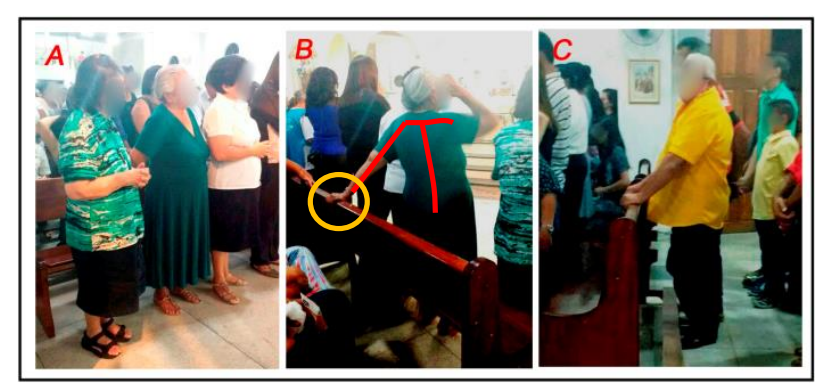

Figura 4: tarefa de ficar de pé. Fonte: elaborado pelos autores para a pesquisa (2016).

Ficando muito tempo de pé, os idosos podem ter a circulação dos membros inferiores prejudicada, o que faz com que sintam dores, inchaço e varizes nesta região.

\subsubsection{Sentar-se}

$\mathrm{O}$ ato de sentar-se, supostamente uma tarefa simples de ser desempenhada, realmente não demanda tanto esforço físico. Neste caso, o que pode ser mais prejudicial é o permanecer sentado, pois, como mostra a figura 10 , as dimensões do banco mostraram-se insuficientes para os idosos de maior estatura, e um pouco exorbitantes para os de menor estatura. Isto torna a atividade desconfortável, pois, uma vez que o idoso não alcança o pé no chão, os vasos sanguíneos da parte posterior da coxa e região poplítea sofrem uma $16^{\circ}$ Ergodesign - Congresso Internacional de Ergonomia e Usabilidade de Interfaces Humano Tecnológica: Produto, Informações Ambientes Construídos e Transporte

$16^{\circ}$ USIHC - Congresso Internacional de Ergonomia e Usabilidade de Interfaces Humano Computador

CINAHPA | 2017 - Congresso Internacional de Ambientes Hipermídia para Aprendizagem. compressão (figura $10[\mathrm{C}]$ ), podendo causar dores, sensação de formigamento, inchaço, problemas circulatórios e até varizes nos membros inferiores. Ao tentar evitar isso, recorrendo ao genuflexório como apoio para os pés, o idoso assume uma postura prejudicial à coluna lombar, uma vez que perde o apoio do encosto do banco como mostra a figura $10(\mathrm{~B})$.

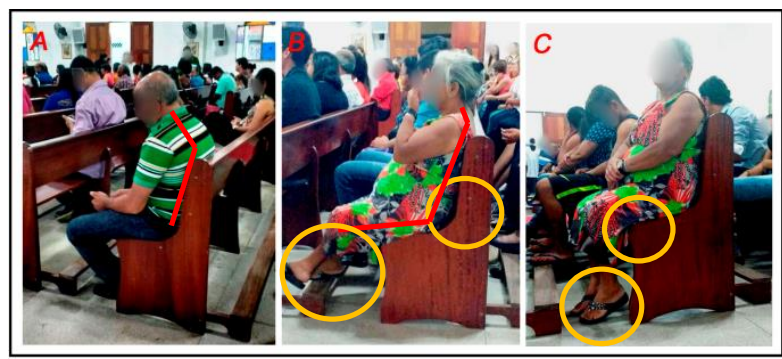

Figura 5: tarefa de sentar-se. Fonte: elaborado pelos autores para a pesquisa (2016).

Foi observado também que o fato do assento não possuir apoio para os braços, dificulta ainda mais para a manutenção de uma boa postura, pois na ausência do apoio, o idoso pode apoiar os braços nos membros inferiores, assumindo, assim, uma postura inadequada como visto na figura 10 (A).

\subsubsection{Circular pela igreja}

A tarefa de circular pela igreja, necessária em momentos como a comunhão e as saudações de paz, mostrou-se dificultosa, pelo fato do ambiente da igreja não oferecer uma boa circulação interna, apresentando dimensões reduzidas em locais que recebe grande fluxo pessoas. Além disso, em algumas partes, o piso apresenta desníveis (figura 11 [A]), a partir de onde passa a ser composto por um material diferente, o granito, que é mais liso e pode fazer o idoso escorregar e cair, vindo a sofrer alguma lesão. Há também, no vão central de circulação onde existe o maior fluxo de pessoas na hora da comunhão, a presença de um tapete que não é fixado uniformemente ao piso (figura 11 [B]), que pode também oferecer perigo de quedas.
Realização:

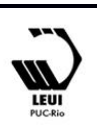




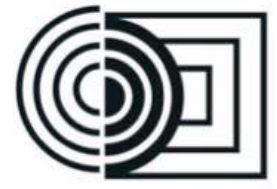

$16^{\circ}$ Ergodesign - Congresso Internacional de Ergonomia e Usabilidade de Interfaces Humano Tecnológica: Produto, Informações Ambientes Construídos e Transporte

$16^{\circ}$ USIHC - Congresso Internacional de Ergonomia e Usabilidade de Interfaces Humano Computador

CINAHPA | 2017 - Congresso Internacional de Ambientes Hipermídia para Aprendizagem.

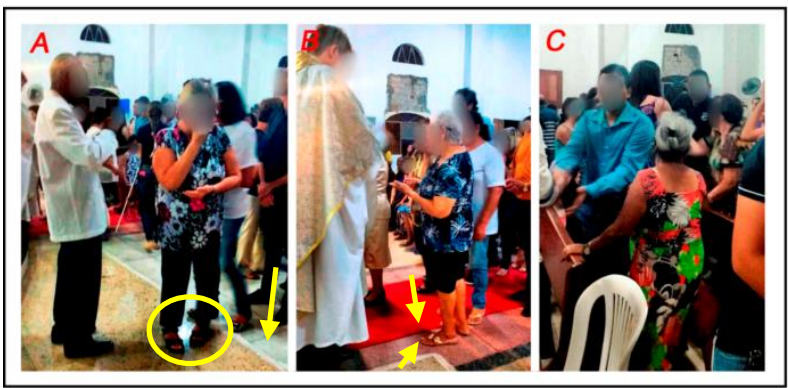

Figura 6: tarefa de circular pela igreja. Fonte: elaborado pelos autores para a pesquisa (2016).

Durante a saudação de paz (figura $11[\mathrm{C}]$ ), a pouca distância entre os bancos, dificulta a circulação e oferece alguns riscos, podendo fazer com o que o idoso venha a cair por não conseguir se movimentar de maneira adequada com bastante espaço e sem barreiras físicas.

\subsubsection{Conforto Ambiental}

Nesta fase, os níveis de iluminação, temperatura e ruído foram aferidos no local. A iluminação, medida nos dois horários de início das missas do domingo ( $8 \mathrm{~h}$ e $17 \mathrm{~h}$ ), com a luz natural que entra pelas janelas e a luz artificial das lâmpadas fluorescentes atuando em conjunto. $\mathrm{O}$ valor alcançou 65 lux pela manhã, e 40 lux à tarde, mostrando-se, portanto, insuficiente, de acordo com os níveis indicados pela Associação Brasileira de Normas e Técnicas (ABNT) - NBR ISO/CIE 8995-1 (2013), para locais de celebração de cultos religiosos, que é de 100 lux para o corpo do local, e 300 lux para o púlpito. A iluminação também apresentou números muito abaixo dos valores indicados para leitura que, segundo a norma regulamentadora, é de 500 lux.

A temperatura, verificada também às $8 \mathrm{~h}$ e às $17 \mathrm{~h}$, era de $24^{\circ} \mathrm{C}$ pela manhã, e à tarde atingia os $27^{\circ} \mathrm{C}$, estando portando, acima dos índices recomendados pera NR 17, que é de uma temperatura efetiva entre $20^{\circ} \mathrm{C} \mathrm{e} 23^{\circ} \mathrm{C}$. A temperatura do ambiente, porém, sofre interferência da ventilação artificial proveniente dos 8 ventiladores de parede dispostos nas paredes leste e oeste, e da ventilação natural proveniente das janelas abertas. A velocidade do ar medida nestas condições alcançou $11,8 \mathrm{~m} / \mathrm{s}$, ultrapassando demasiadamente a recomendação da NR 17, que indica uma velocidade do ar não superior a $0,7 \mathrm{~m} / \mathrm{s}$.

Os níveis de ruído verificados no decorrer das celebrações, apresentaram, durante as leituras, o mínimo de $44 \mathrm{~dB}$, e o máximo de $86 \mathrm{~dB}$, e durante os cânticos apresentaram mínimo de $47 \mathrm{~dB}$ e máximo de $91 \mathrm{~dB}$. Como as celebrações costumam durar em torno de $1 \mathrm{~h} 40 \mathrm{~min}$ e $2 \mathrm{~h}$, nesses intervalos de tempo, de acordo com a NR 15, os níveis registrados no local estão dentro dos limites de tolerância para ruído contínuo ou intermitente, que são de $95 \mathrm{~dB}$ e $96 \mathrm{~dB}$.

\subsubsection{Análise Antropométrica da igreja}

No intuito de avaliar o ambiente da igreja com maior completude, com os dados dimensionais coletados no local, foi feita uma comparação com as dimensões recomendadas por Panero e Zelnik (2013).

Com relação aos bancos, que normalmente comportam quatro pessoas, foi verificado que a largura do encosto apresenta $2 \mathrm{~m}$, oferecendo apenas $50 \mathrm{~cm}$ para cada usuário, estando em desacordo com as medidas estabelecidas por Panero e Zelnik (2013) para bancos de alta densidade, que recomendam uma largura total de 2,44 m, garantindo, assim, uma largura individual de $61 \mathrm{~cm}$. A profundidade do assento, que possui $36 \mathrm{~cm}$, mostrou-se também inferior às dimensões recomendadas pelos autores, que estipulam uma profundidade de 39,4 a 40,6 cm. A altura do assento, medindo $44 \mathrm{~cm}$, ultrapassou a altura recomendada, que figura entre $40,6 \mathrm{~cm}$ e 43,2 cm.

A área de circulação central, principal via de acesso dos usuários aos seus assentos e onde são formadas duas filas no momento da comunhão, possui 2,05 m. Deste modo, enquadra-se dentro das recomendações para zonas de movimentação com passagem para duas pessoas, estabelecidas por Panero e Zelnik (2013), que é de 1,72 m, no entanto, em diversos momentos, o fluxo concomitante vai além de duas pessoas. A circulação periférica possui $2,50 \mathrm{~m}$ até o ponto

\section{Realização: "-




\section{$16^{\circ}$ \\ ERGODESIGN USIHC CINAHPA}

$16^{\circ}$ Ergodesign - Congresso Internacional de Ergonomia e Usabilidade de Interfaces Humano Tecnológica: Produto, Informações Ambientes Construídos e Transporte

$16^{\circ}$ USIHC - Congresso Internacional de Ergonomia e Usabilidade de Interfaces Humano Computador

CINAHPA | 2017 - Congresso Internacional de Ambientes Hipermídia para Aprendizagem. onde as fileiras passam a ter dois bancos, e até este ponto a circulação está adequada para o fluxo concomitante de até três pessoas, de acordo com os autores, que estabelecem $2,43 \mathrm{~m}$. A partir desse ponto o corredor passa a ter $1,05 \mathrm{~m}$, estando adequado para o fluxo de apenas uma pessoa por vez, onde Panero e Zelnik (2013) sugerem uma largura de 76,2 e 91,4 cm. Apesar de algumas áreas de circulação oferecerem dimensões satisfatórias para fluxo de simultâneo de duas e três pessoas, estas dimensões mostraram-se desconfortáveis em momentos de grande movimentação como a comunhão, e a evacuação da igreja ao final das cerimônias.

\subsection{Adaptação às Necessidades do Usuários}

Através das etapas anteriores, foi possível observar alguns problemas e inadequações no ambiente, que agem como fatores limitantes, causando

desconforto e induzindo o idoso a assumir posturas prejudiciais à sua saúde e bem-estar.

Um dos problemas é decorrente das dimensões do assento, por serem inferior às recomendadas. Além disso, a falta de acolchoado nos bancos, tende a gerar grandes desconfortos nos membros inferiores e coluna vertebral quando sua utilização é prolongada, pois a madeira é um material muito rígido. Também foi observado que a ausência de braços no assento prejudica o idoso, pois este fica sem nenhum tipo de apoio que o auxilie a levantarse ou sentar-se.

O genuflexório é apontado como outro elemento problemático, por não ser disponibilizado em alguns setores da igreja, e, quando presente, pelo desconforto causado devido também ao material de composição rígido, e ausência de acolchoado. Outro problema é fato de reduzir o espaço entre os bancos, já bastante insuficiente, inadequado e propício a causar tombos ou acidentes durante a circulação. Quanto aos espaços de circulação, estes, em sua maioria, apresentaram alguns problemas, mostrando-se, mesmo os que atendem a determinadas recomendações, desconfortáveis devido ao fato de o fluxo de pessoas muitas vezes exceder o limite para a circulação concomitante a que eles se adéquam. Além disso, na área de circulação central, a existência de um tapete não fixado ao piso de maneira uniforme oferece riscos de quedas.

Observou-se que o layout é também problemático, pois induz os usuários acomodados mais próximos ao presbitério a realizar uma rotação do pescoço para uma melhor visualização do altar, o que durante períodos demorados pode gerar dores na região cervical. $\mathrm{O}$ piso apresentou riscos no que se refere ao material de composição do presbitério, possuindo brilho e pouca aderência, e apresentando, além disso, alguns desníveis.

A iluminação, de acordo com as normas vigentes, está inadequada, pois mostrou-se muito inferior aos níveis recomendados para este tipo de ambiente. A temperatura verificada encontrou-se acima níveis sugeridos, acarretando em uma sensação de desconforto térmico. A interferência da ventilação alcançou uma velocidade do ar superior à indicada, estando inadequada. Os níveis de ruído mantiveram-se dentro dos limites tolerados para o tempo de duração das celebrações.

A cor branca, predominante nas paredes do ambiente, cria a sensação de frieza, monotonia e impessoalidade. A cor cinza do piso mostrou-se adequada por conotar solidez e estabilidade, assim como a cor marrom do mobiliário e do teto, pois cria a sensação de introspecção e sobriedade, podendo inclusive, a depender da tonalidade, tornar o ambiente acolhedor. A junção das cores se mostraram neutras e amenas, mas pouco estimulantes.

Levando em conta todos os problemas relatados aqui, a partir das informações colhidas no local e das observações das tarefas, fica evidente a necessidade de adaptações focadas na correção dos problemas que dificultam a utilização do ambiente da igreja pelos usuários idosos.

Isto posto, foi realizada a seguinte Lista de Recomendações Ergonômicas:
Realização:

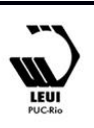


$16^{\circ}$ Ergodesign - Congresso Internacional de Ergonomia e Usabilidade de Interfaces Humano Tecnológica: Produto, Informações Ambientes Construídos e Transporte

$16^{\circ}$ USIHC - Congresso Internacional de Ergonomia e Usabilidade de USIHC Interfaces Humano Computador

CINAHPA | 2017 - Congresso Internacional de Ambientes Hipermídia para Aprendizagem.

Organizar o layout de modo que este assuma uma configuração em arco em volta do altar (arena), facilitando a visualização por parte do público.

Dispor os bancos com uma distância mínima de 76,2 a 91,4 cm entre um e outro, de modo que atenda de maneira confortável a circulação de uma pessoa.

Oferecer uma ampla área de circulação central onde há maior fluxo de transeuntes, e uma circulação lateral uniforme que ofereça ao longo de toda sua área de abrangência dimensões confortáveis e não variantes.

Bancos acolchoados, com braços individuais, e com dimensões adequadas para largura do encosto do assento $(61 \mathrm{~cm}$ para cada pessoa), profundidade do assento (entre $39,4 \mathrm{~cm}$ e 40,6 cm), e altura do assento (entre 40,6 cm e 43,2 cm)

Genuflexório em todos os locais necessários, sendo este mais elevado, e possuindo acolchoado que minimize o desconforto causado pela atividade de se ajoelhar, devendo contar, também, com hastes e alças de apoio.

Eliminar desníveis presentes no piso, de modo que este seja o mais plano e nivelado possível.

Evitar materiais brilhosos ou escorregadios para o piso, dando preferência a materiais aderentes e antiderrapantes.

Na presença de elementos como tapetes, certificar-se que estes estejam totalmente fixados ao piso.

Corrigir a iluminação ampliando a quantidade lâmpadas fluorescentes e luminárias, para que ofereça sempre 500 lux em locais de leitura, garantindo, assim, os 100 lux para o corpo do local, e 300 lux para o púlpito, como recomendado pela norma.

Fazer uso de basculantes, treliças/persianas fixas para controlar a elevada velocidade do ar que penetra no ambiente através das janelas.

Controlar a temperatura por meio da instalação de ar-condicionado, mantendo-o entre $20^{\circ} \mathrm{C}$ e $23^{\circ} \mathrm{C}$

Manter os níveis de ruído dentro dos limites de 95 dB e 96 dB tolerados para ruído contínuo ou intermitente, de acordo com a duração de cada celebração, como recomenda a NR 15 , controlando o volume do som emitido pelos microfones e instrumentos da banda pelas caixas amplificadoras.

Introduzir cores ao ambiente de maneira equilibrada, como tons de amarelo ou laranja que são cores dinâmicas, estimulantes, e proporcionam vitalidade, ou tons de azul que promovem a sensação de serenidade e paz.

Tabela 1: Lista de recomendações ergonômicas.

\section{Conclusões}

A partir de uma pesquisa aprofundada de estudos bibliográficos já publicados relacionados ao envelhecimento, foi possível reunir informações sobre as limitações decorrentes deste processo biológico a que os seres humanos estão sujeitos. Munido destas informações, alinhadas aos conhecimentos em Ergonomia do Ambiente Construído, foi possível, através da análise do ambiente feita sob a luz da metodologia utilizada, apontar os prejuízos ergonômicos causados pelo uso do ambiente interno da igreja por parte dos usuários idosos.

A aplicação da metodologia mostrou-se um pouco difícil, pelo fato dos autores (até o momento desta pesquisa) oferecerem as etapas, mas não explicarem detalhadamente os procedimentos, $o$ que acaba exigindo do pesquisador uma sensibilidade para identificar e aplicar os procedimentos adequados à situação analisada.

Com base nos resultados da aplicação metodológica, que apontou os diversos problemas no ambiente, ficou evidente a necessidade de adaptações, sendo, então, estabelecida uma lista de recomendações ergonômicas a serem consideradas para a concepção do ambiente interno de igrejas.

Ficaram claras as dificuldades relacionadas à utilização do ambiente, que se não forem solucionadas através de uma intervenção ergonômica focada no conforto de seus usuários, podem vir a causar uma série de fatores complexos e negativos. Cabendo uma reflexão sobre como o idoso se sente física e psicologicamente utilizando um ambiente que não o considera em seu projeto.

Sabemos que as tarefas executadas no ambiente da igreja, algumas identificadas como cansativas (como permanecer de pé por períodos prolongados), fazem parte dos ritos das celebrações nas igrejas católicas, e aqui não pretendemos invalidar, tolher ou dizer que o idoso deixe de realizá-las, pois apesar de possuírem algumas limitações, eles têm o direito de escolher se as cumprem ou não. Contudo, sugerimos que as necessidades dos idosos sejam levadas em consideração, para que, caso o idoso permaneça motivado na realização das tarefas, essas sejam o mais confortáveis e facilitadas possível. 


\section{$16^{\circ}$ \\ ERGODESIGN \\ USIHC CINAHPA}

Torna-se imprescindível que as instituições que comandam as igrejas (paróquias, dioceses), proponham a aplicação desse tipo de recomendações. Também seria importante que fosse criado nas dioceses um setor de ergonomia, a fim de que possíveis lesões, acidentes, e constrangimentos físicos e psicológicos sejam evitados.

\section{Referências bibliográficas}

ATTAIANESE, E.; DUCA, G. Human factors and ergonomic principles in building design for life and work activities: an applied methodology. Theoretical Issues in Ergonomics Science. Vol. 13, No. 2, March-April 2012, 187-202.

BARALDI, G. S.; ALMEIDA, L. C.; BORGES, A. C. C. Evolução da perda auditiva no decorrer do envelhecimento. Rev Bras Otorrinolaringol. 2007; 73 (1): 64-70.

BONARDI, G.; AZEVEDO E SOUZA, V. B.; MORAES, J. F. D. Incapacidade funcional e idosos: um desafio para os profissionais de saúde. Scientia Medica, Porto Alegre, v. 17, n. 3, p. 138144, jul./set. 2007.

\section{COUTO, L. Professor de história explica a} presença da Igreja Católica no Brasil. 2012. Disponível em:

<http://g1.globo.com/pernambuco/vestibular-eeducacao/noticia/2012/10/professor-de-historiaexplica-presenca-da-igreja-catolica-no-brasil.html> Acesso em 12 out. 2016.

ESQUENAZI, D.; SILVA, S. R. B.; GUIMARÃES, M. A. M. Aspectos fisiopatológicos do envelhecimento humano e quedas em idosos. Revista HUPE, Rio de Janeiro, 2014; 13 (2): 11-20.

IIDA, Itiro. Ergonomia: projeto e produção. São Paulo: Editora Blücher, 2005.

LIMA, M. A. M. O espaço celebrativo segundo a imagem da igreja. Contemplação. n. 1. 2010.

MILANI, E. M. Arquitetura, luz e liturgia: um estudo da iluminação nas igrejas católicas / Eliva $16^{\circ}$ Ergodesign - Congresso Internacional de Ergonomia e Usabilidade de Interfaces Humano Tecnológica: Produto, Informações Ambientes Construídos e Transporte

$16^{\circ}$ USIHC - Congresso Internacional de Ergonomia e Usabilidade de Interfaces Humano Computador

CINAHPA | 2017 - Congresso Internacional de Ambientes Hipermídia para Aprendizagem.

de Menezes Milani. Rio de Janeiro: UFRJ/FAU, 2006.

MORAES, N. A. S. Velhice: qualidade de vida intrínseca e extrínseca. Boletim de Psicologia, 2007, Vol. LVII, No 127: 215-238.

MORAES, E. N. Processo de envelhecimento e bases da avaliação multidimensional do idoso.

Envelhecimento e Saúde da Pessoa Idosa. Rio de Janeiro: Fiocruz/ENSP/EAD; 2008.

ORGANIZAÇÃO MUNDIAL DA SAÚDE. Relatório Mundial de Envelhecimento e Saúde. 2015.

PAIVA, M. M. B.; VILLAROUCO, V. Ergonomia no ambiente construído em moradia coletiva para idosos: estudo de caso em Portugal. Ação

Ergonômica, v. 7, n. 3, 2012.

PANERO, J.; ZELNIK, M. Dimensionamento humano para espaços interiores: um livro de consulta e referência para projetos. Gustavo Gili, 2013.

POLATO, Danielle. Avaliação objetiva do tônus muscular em idosos praticantes de atividade física. Rio de Janeiro: UFRJ/COPPE, 2010.

SOBRAL, E. R. A.; PAIVA, M. M. B.; PORTO, N. R. S.; VILLAROUCO, V. Discussão acerca da percepção ambiental, suas ferramentas e cognição, p. 34-44. In: Anais do $\mathbf{1 5}^{\circ}$ Ergodesign \& Usihc [Blucher Design Proceedings, vol. 2, num 1.]. São Paulo: Blucher, 2015.

VERAS, R. Envelhecimento populacional contemporâneo: demandas, desafios e inovações.

Rev Saúde Pública, 43(3):548-54, 2009.

VILLAROUCO, V. O que é um ambiente ergonomicamente adequado? I Conferência Latino-americana de Construção Sustentável X Encontro Nacional de Tecnologia do Ambiente Construído. 18-21 julho 2004, São Paulo.

Reflexões acerca da ergonomia do ambiente construído. In: Boletim da Associação Brasileira de Ergonomia. Recife: Abergo, 2007.
Realização:

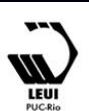

